\title{
Consumo, digestibilidade aparente dos nutrientes e balanço hídrico em equinos alimentados com feno de coast-cross em diferentes formas ${ }^{1}$
}

\section{Róbson Ricardo Moreira Pimentel ${ }^{2}$, Fernando Queiroz de Almeida ${ }^{3}$, Antonio Assis Vieira ${ }^{4}$, Ana Paula Pessim de Oliveira ${ }^{5}$, Fernanda Nascimento de Godoi ${ }^{5}$, Almira Biazon França ${ }^{5}$}

\footnotetext{
${ }^{1}$ Apoio financeiro da Fundação de Amparo à Pesquisa do Estado do Rio Janeiro.

2 Programa de Pós-Graduação em Zootecnia, UFRRJ.

3 Instituto de Veterinária, UFRRJ. BR 465, Km 07, Seropédica, RJ.

4 Instituto de Zootecnia, UFRRJ.

${ }^{5}$ Curso de Zootecnia na UFRRJ. Bolsista de Iniciação Científica PIBIC-CNPq/UFRRJ.
}

RESUMO - Este trabalho foi realizado com o objetivo de avaliar o consumo, a digestibilidade aparente dos nutrientes e o balanço hídrico em equinos consumindo feno de capim coast-cross em diferentes formas físicas. Foram utilizados quatro equinos mestiços, com idade de 30 meses e peso vivo médio de $200 \mathrm{~kg}$. Os animais foram alimentados com feno de capim coast-cross em quatro formas físicas: inteiro; picado $(5 \mathrm{~cm})$; moído a $5 \mathrm{~mm}$; ou moído a $3 \mathrm{~mm}$. O delineamento experimental utilizado foi em quadrado latino $4 \times 4$, com 10 dias de adaptação às dietas em cada período experimental, 4 dias de coleta de fezes e 1 dia de coleta de urina. A estimativa da digestibilidade aparente dos nutrientes das dietas foi realizada pelo método de coleta total das fezes e a urina foi coletada durante 24 horas utilizando-se coletores de urina. Os coeficientes de digestibilidade aparente e o consumo de nutrientes não diferiram com o processamento do feno, no entanto, o tempo de consumo reduziu com a moagem do feno. Houve maior retenção de água, estimada pelo balanço hídrico, quando fornecido feno picado ou moído a $3 \mathrm{~mm}$. O consumo e a digestão dos nutrientes não são influenciados pelo nível de moagem do feno, porém o balanço hídrico é afetado pelas formas físicas do feno. Não há relação direta entre a redução do tamanho da partícula do feno e o aumento da retenção de água

Palavras-chave: digestão, fibra digestível, tamanho de partícula

\section{Intake, apparent nutrient digestibility and water balance in horses fed on different forms of coast-cross hay}

\begin{abstract}
This study was carried out to evaluate intake, apparent nutrient digestibility and water balance in horses fed on different forms of coast-cross hay. Four crossbreed horses, 30 months of age and $200 \mathrm{~kg}$ body weight were used. Horses were fed coast-cross hay in four physical forms: long hay; chopped hay (5 cm); ground hay (5 $\mathrm{mm})$ and ground hay (3 mm). The experiment was performed in a $4 \times 4$ Latin Square design with 15 days for each experimental period (10 days for adaptation to the diets, four days for feces collection and one day for urine collection). Apparent nutrient digestibility was estimated by total feces collection and urinary collection was carried during 24 hours by urine collectors. Apparent digestibility coefficients and nutrient intake did not differ among the diets but the intake time was reduced with hay processing. There was greater water retention, estimated by water balance, when chopped hay or ground hay ( $3 \mathrm{~mm})$ were fed. Intake and nutrient digestibility were not influenced by levels of hay grinding, but water balance was influenced by the different forms of hay, but a direct relationship was not observed between fiber length reduction and increased water retention
\end{abstract}

Key Words: digestion, digestible fiber, particle size

\section{Introdução}

Com a expansão da indústria equina, novas formas de processamento das forragens estão sendo adotadas com o objetivo, principalmente, de resolver problemas relacionados ao espaço para armazenamento e ao manuseio trabalhoso, uma vez que as atividades equestres se mantêm nos grandes centros urbanos, em jóqueis clubes e centros hípicos. O processamento dos alimentos, principalmente dos volumosos utilizados na alimentação dos equinos, como a moagem ou a peletização, podem reduzir substancialmente o volume do material facilitando a estocagem e o manuseio.

Em ruminantes, a diminuição do tamanho de partícula tem efeito negativo sobre a digestibilidade dos nutrientes, principalmente os da parede celular vegetal, o que, segundo 
Udén (1988), está relacionado ao menor tempo de permanência do material finamente moído no rúmen, diminuindo o tempo de fermentação e a digestibilidade dos carboidratos estruturais. Em herbívoros, usualmente o aumento no tempo médio de retenção das partículas da forragem contribui para o aumento da digestão da fibra (Fombelle et al., 1999).

A forma como o volumoso é fornecido aos equinos pode influenciar o consumo, a duração, a velocidade e a dinâmica do fluxo da digesta nos segmentos e em todo o trato digestório e consequentemente a eficiência da ação microbiana e a disponibilidade de nutrientes, principalmente a energia dos alimentos volumosos. O tempo de consumo em animais estabulados é influenciado por fatores ambientais e fatores ligados ao comportamento individual. A forma física do alimento e a frequência de fornecimento podem alterar o tempo de mastigação e o tempo de trânsito da digesta, afetando o tempo de consumo. Essas mudanças podem favorecer ou não a ocorrência de vícios e distúrbios digestivos em animais estabulados.

Entre os alimentos volumosos utilizados atualmente para equinos, o capim coast-cross tem sido utilizado na formação de pastagens e pode ser empregado na forma de feno como alimento único na dieta de eqüinos em mantença. O objetivo neste trabalho foi avaliar os efeitos do fornecimento do feno de coast-cross (Cynodon dactylon, L.) em diferentes formas físicas sobre o consumo, a digestibilidade aparente dos nutrientes e o balanço hídrico em equinos.

\section{Material e Métodos}

O experimento foi conduzido no Laboratório de Pesquisas em Saúde Eqüina da Universidade Federal Rural do Rio de Janeiro, no período de setembro a novembro de 2004, e as análises químicas foram realizadas no Laboratório de Bromatologia do Instituto de Zootecnia da UFRRJ. Durante o período experimental, as médias das temperaturas máximas e mínimas foram de $34,6^{\circ} \mathrm{C}$ e $28,35^{\circ} \mathrm{C}$, respectivamente, e a umidade média do ar foi de $78 \%$.

O ensaio de digestão foi realizado em baias individuais de alvenaria com piso de cimento, de $3 \mathrm{~m} \times 3 \mathrm{~m}$, pé-direito de $3 \mathrm{~m}$, com cochos separados para ração e água. Foram utilizados quatro equinos mestiços, machos, com peso vivo médio de $200 \mathrm{~kg}$ e 30 meses de idade. Os animais foram submetidos à doma de baixo e exercitados ao passo e ao trote, uma vez por dia, por 30 minutos no período da manhã, e receberam o mesmo manejo no período pré-experimental: recuperação do escore corporal, imunização contra tétano, vermifugação e pulverização contra ectoparasitos.

O feno de coast-cross foi fornecido aos animais como dieta exclusiva. No início do período de adaptação, os animais receberam o feno à vontade para regulação do consumo. Após o período de ajuste, o feno foi fornecido em quantidade equivalente a $2,5 \%$ do peso vivo, com base na matéria seca. A água foi fornecida à vontade e o suplemento mineral $\left(\right.$ Omolene $\left.{ }^{\circledR}\right)$ foi fornecido na quantidade de $50 \mathrm{~g} / \mathrm{animal} / \mathrm{dia}$.

Os tratamentos experimentais consistiram das formas físicas do feno de coast-cross: inteiro; picado em partículas de aproximadamente $5 \mathrm{~cm}$; moído em peneira com crivos de $5 \mathrm{~mm}$ de diâmetro; finamente moído em peneira com crivos de $3 \mathrm{~mm}$ de diâmetro (Tabela 1). O feno picado foi processado em picadeira elétrica para forragem, o feno moído processado em moinho elétrico para grãos utilizando duas peneiras com diâmetro de furo de 5 e $3 \mathrm{~mm}$, respectivamente, para os fenos classificados como moído e finamente moído. O feno de coast-cross foi oferecido aos equinos quatro vezes ao dia, em quantidades iguais, nos horários de 1, 7, 13 e $19 \mathrm{~h}$.

Cada período experimental teve duração de 15 dias: 10 dias de adaptação, seguidos de 4 dias de coleta total de fezes e 1 dia de coleta de urina. No $10^{\circ}$ dia de cada período experimental, foi realizado o controle do consumo após o fornecimento do feno, a cada hora, até o consumo total.

Os coeficientes de digestibilidade aparente dos nutrientes das dietas foram estimados pelo método de coleta total de fezes (Maurício et al., 1996). A coleta de fezes foi realizada a partir do $11^{\underline{0}}$ dia de cada período experimental, durante quatro dias. As fezes dos animais foram coletadas utilizando-se coletores apropriados para equinos. A cada 6 horas, as fezes de cada animal foram pesadas e homogeneizadas para retirada de uma amostra correspondente a $10 \%$ do peso total das fezes colhidas de cada animal. Essas amostras foram armazenadas em sacos plásticos individuais a $-18^{\circ} \mathrm{C}$ e, ao término de cada dia de

Tabela 1 - Composição bromatológica, em porcentagem da matéria seca, do feno de coast-cross

\begin{tabular}{lccccccccc}
\hline Alimento & \multicolumn{8}{c}{ Composição (\%) } \\
\cline { 2 - 9 } & $\begin{array}{c}\text { Matéria } \\
\text { seca }\end{array}$ & $\begin{array}{c}\text { Matéria } \\
\text { orgânica }\end{array}$ & $\begin{array}{c}\text { Proteína } \\
\text { bruta }\end{array}$ & $\begin{array}{c}\text { Fibra em } \\
\text { detergente neutro }\end{array}$ & $\begin{array}{c}\text { Fibra em } \\
\text { detergente ácido }\end{array}$ & Hemicelulose & Celulose & $\begin{array}{c}\text { Lignina } \\
\text { Energia } \\
\text { bruta, Mcal/kg }\end{array}$ \\
\hline Feno de coast-cross & 86,1 & 92,8 & 12,2 & 70,7 & 29,3 & 41,5 & 25,7 & 4,1 & 4,288 \\
\hline
\end{tabular}


coleta, as quatro amostras de cada animal foram homogeneizadas, retirando-se uma amostra composta diária de cada animal com aproximadamente $300 \mathrm{~g}$, que em seguida foi armazenada a $-18^{\circ} \mathrm{C}$.

A água foi fornecida à vontade em baldes de capacidade conhecida e renovada três vezes ao dia às 7 , 13 e $19 \mathrm{~h}$, durante cinco dias, e as sobras medidas diariamente às $7 \mathrm{~h}$ para cálculo do consumo diário. No 15 - dia de cada período experimental, a urina foi colhida durante 24 horas, utilizando-se coletores de borracha semelhantes aos descritos por Tasker (1966). A urina foi recolhida em recipientes plásticos contendo $25 \mathrm{~mL}$ de HCL $5 \mathrm{M}$ e, a cada período de 12 horas, foi coletada alíquota de aproximadamente $100 \mathrm{~mL}$, que foi posteriormente armazenada $-18^{\circ} \mathrm{C}$.

O consumo total de água foi calculado pela soma da água livre consumida e a água presente no alimento. $\mathrm{O}$ total de água excretada foi calculado em análise do teor de matéria seca da urina e o teor de matéria seca das fezes.

O balanço hídrico foi avaliado utilizando-se as seguintes equações:

Consumo total de água (litros/dia) = água consumida no cocho + água consumida no alimento

Excreção total de água (litros/dia) = água urina

$$
(\% \mathrm{MS})+\text { água fezes }(\% \mathrm{MS})
$$

Balanço hídrico $($ litros/dia $)$ consumo total água excreção total de água

Ao término do período experimental, as amostras diárias de fezes de cada animal foram descongeladas à temperatura ambiente e homogeneizadas para retirada de uma amostra composta, que foi pesada, colocada em recipientes de alumínio e pré-seca em estufa de ventilação forçada a $55^{\circ} \mathrm{C}$, durante 72 horas. Posteriormente, as amostras foram trituradas em moinho tipo Willey a $1 \mathrm{~mm}$ e acondicionadas em frascos plásticos etiquetados até as análises. Do feno de coast-cross oferecido aos animais, amostras foram retiradas e armazenadas a $-18^{\circ} \mathrm{C}$. Ao final do período experimental, as amostras foram descongeladas à temperatura ambiente e, posteriormente, moídas e acondicionadas em frascos plásticos etiquetados.

As análises de matéria seca (MS), matéria orgânica $(\mathrm{MO})$, proteína bruta $(\mathrm{PB})$ e energia bruta $(\mathrm{EB})$ nas amostras do feno e das fezes foram realizadas segundo metodologia descrita pela AOAC (1975), e as de fibra em detergente neutro (FDN), fibra em detergente ácido (FDA), de forma sequencial, e as de lignina (LIG), segundo Van Soest et al. (1991).

Os coeficientes de digestibilidade aparente (CD) dos nutrientes foram calculados de acordo com Schneider \& Flatt (1975), com a seguinte equação:
MS dieta $\times(\%$ nutriente na dieta $)-$ MS fezes $\times$ (\% nutriente nas fezes)

$$
\mathrm{CD}(\%)=\frac{\text { MS dieta } \times(\% \text { nutriente na dieta })}{} \times 100
$$

Utilizou-se o delineamento experimental em quadrado latino $4 \times 4$, com quatro tratamentos (feno de coast-cross com diferentes formas físicas) e quatro animais, considerando o animal a unidade experimental. O modelo estatístico adotado foi Yijk $=\mu+\mathrm{Pi}+\mathrm{Aj}+\mathrm{Dk}+$ eijk, em que Yijk corresponde à observação relativa à dieta $\mathrm{k}$, no período $\mathrm{i}$, para o animal $\mathrm{j} ; \mu=$ média geral; $\mathrm{P} i=$ efeito do período $\mathrm{i}$ $(\mathrm{i}=1 \mathrm{a} 4) ; \mathrm{Aj}=\mathrm{o}$ efeito do animal $\mathrm{j}(\mathrm{j}=1 \mathrm{a} 4) ; \mathrm{Dk}=\mathrm{o}$ efeito da dieta $\mathrm{k}(\mathrm{k}=1 \mathrm{a} 4)$; e Eijk = o erro experimental associado a cada observação

Os valores médios do consumo, dos coeficientes de digestibilidade aparente dos nutrientes e do balanço hídrico foram submetidos à análise de variância e comparados pelo teste de Student-Newman Keuls, adotando o nível de $5 \%$ de probabilidade. As análises estatísticas foram realizadas utilizando-se o programa SAEG - Sistema de Análises Estatísticas e Genéticas (UFV, 2004).

\section{Resultados e Discussão}

Não houve diferença $(\mathrm{P}>0,05)$ no consumo de matéria seca e demais nutrientes do feno de coast-cross em diferentes tamanhos da partícula do feno (Tabela 2). O consumo médio de matéria seca foi de $4,84 \mathrm{~kg} / \mathrm{dia}$ ou de $2,27 \mathrm{~kg}$ de MS/100 kg de peso vivo. As recomendações do NRC (1989) para o consumo médio diário de matéria seca são de 2,0 a 2,5 kg de MS/100 kg de peso vivo.

Segundo Meyer (1995), a capacidade de ingestão média diária de matéria seca de equinos de porte médio em mantença é de 2,0 kg de MS/100 kg de peso vivo. Haenlein et al. (1966) observaram aumento significativo no consumo de matéria seca com a diminuição do tamanho de partícula da forragem quando o feno foi fornecido inteiro, moído e prensado ou moído e peletizado, com valores de 2,23;2,77 e 2,62 kg de MS/100 kg de PV, respectivamente.

Tood et al. (1995) avaliaram o consumo do feno de alfafa em três formas: feno longo, feno picado, feno moído prensado na forma de cubos e na forma de péletes e observaram aumento de consumo do feno em cubo em relação às outras formas do feno, com valores de 2,54; 2,$70 ; 3,20$ e $2,52 \mathrm{~kg} \mathrm{MS} / 100$ de peso vivo, respectivamente.

O valor observado para o consumo voluntário foi superior ao observado por Almeida et al. (1999), que forneceram feno de capim coast-cross à vontade para equinos adultos e registraram consumo voluntário de 1,39\% 
Tabela 2 - Consumo médio de nutrientes e tempo de consumo em equinos alimentados com feno de coast-cross em diversas formas físicas

\begin{tabular}{|c|c|c|c|c|c|}
\hline Item & \multicolumn{4}{|c|}{ Feno de coast-cross } & Média \\
\hline Matéria seca (kg/dia) & 4,82 & 4,85 & 4,73 & 4,98 & 4,84 \\
\hline Matéria seca $(\mathrm{kg} / 100 \mathrm{~kg} \mathrm{PV})$ & 2,25 & 2,25 & 2,26 & 2,32 & 2,27 \\
\hline Tempo de consumo (horas) & $2,42 \mathrm{a}$ & $1,99 \mathrm{ab}$ & $1,93 \mathrm{ab}$ & $1,11 \mathrm{~b}$ & - \\
\hline Matéria orgânica (kg/dia) & 3,80 & 3,83 & 3,73 & 3,93 & 3,82 \\
\hline Fibra em detergente ácido $(\mathrm{kg} / \mathrm{dia})$ & 1,41 & 1,42 & 1,38 & 1,46 & 1,42 \\
\hline Hemicelulose $(\mathrm{kg} / \mathrm{dia})$ & 2,00 & 2,01 & 1,96 & 2,07 & 2,01 \\
\hline Energia bruta (Mcal/dia) & 20,66 & 20,81 & 20,27 & 21,35 & 20,77 \\
\hline
\end{tabular}

Médias, nas linhas, seguidas de letras diferentes diferem entre si $(\mathrm{P}<0,05)$ pelo teste $\mathrm{SNK}$.

do peso vivo, o que parece ter sido influenciado pelo porte dos animais e pela qualidade do alimento. No entanto, Araújo et al. (2000) observaram consumo médio de 2,23 kg $\mathrm{MS} / 100 \mathrm{~kg}$ de peso vivo em equinos alimentados com dieta única de feno de coast-cross.

O tempo de consumo dos equinos consumindo o feno finamente moído ( $3 \mathrm{~mm}$ ) diferiu $(\mathrm{P}<0,05)$ do observado nos animais consumindo feno inteiro, de 1,11 e 2,42 horas, respectivamente, mas não foram observadas diferenças $(\mathrm{P}>0,05)$ em relação às demais formas físicas. Segundo Haenlein et al. (1966) e Hintz \& Loy (1966), a forma física como um alimento é apresentado altera a taxa de consumo de matéria seca em equinos, que parecem responder mais à forma física ou palatabilidade do alimento que ao conteúdo de energia. De acordo com Frape (1998), os equinos geralmente reduzem o tamanho das partículas do feno e de volumosos frescos a menos de $1,6 \mathrm{~mm}$ de comprimento durante a mastigação e dois terços das partículas de feno no estômago dos equinos são menores que $1 \mathrm{~mm}$.

O consumo médio de proteína bruta foi de $596 \mathrm{~g} / \mathrm{dia}$, valor superior ao recomendado pelo NRC (1989) de $296 \mathrm{~g} /$ dia, para equinos em mantença com peso médio de $200 \mathrm{~kg}$ de PV.

Hintz (1994), com base no conteúdo fibroso dos alimentos volumosos fornecidos aos equinos, sugeriram que a dieta deve ser composta de, no mínimo, $120 \mathrm{~g}$ de fibra bruta (FB) para cada $100 \mathrm{~kg}$ de PV, equivalente a $20 \%$ de FDN e $12 \%$ de FDA na dieta. Neste trabalho, os níveis de FDN e FDA do feno oferecido aos animais foram de 70,73 e $29,26 \%$, respectivamente.

Oliveira (2001) observou em equinos com peso vivo médio de $200 \mathrm{~kg}$ que o uso de feno de coast-cross como dieta única resultou em consumo médio diário de FDN e FDA de 2,76 e 1,35 kg/dia. Segundo Meyer (1995), a quantidade de alimento ingerida é determinada pela densidade energética do alimento, mas, neste ensaio não houve variação do conteúdo de energia do alimento e não foi observado efeito da densidade energética.

Os resultados da análise da digestibilidade mostram que não houve diferença $(\mathrm{P}>0,05)$ entre os coeficientes de digestibilidade dos nutrientes nos equinos alimentados com feno de coast-cross em diferentes formas físicas (Tabela 3). Esses resultados estão de acordo com os observados por Drogoul et al. (2000), que não observaram diferenças $(\mathrm{P}>0,05)$ nos coeficientes de digestibilidade dos nutrientes em pôneis alimentados com feno picado ou feno moído e peletizado, em dietas com iguais proporções de feno de alfafa e feno de cocksfoot.

Tood et al. (1995) não observaram efeito do fornecimento do feno de alfafa peletizado, em cubo, picado e como feno inteiro, sobre os coeficientes de digestibilidade da MS, $\mathrm{PB}, \mathrm{FDN}$ e EB em equinos, o que indica que, quando se utiliza o feno com mesmo valor nutricional e fornecido em mesmo nível de consumo, a diminuição do tamanho da partícula do alimento não tem efeito sobre a digestibilidade dos nutrientes.

No entanto, Haenlein et al. (1966), avaliando o feno de alfafa fornecido prensado (walfer), peletizado ou inteiro para equinos, não observaram efeito da forma física do feno sobre a digestibilidade da MS e PB. Entretanto, o coeficiente de digestibilidade da fibra bruta foi menor quando o feno foi fornecido na forma peletizada, logo a diminuição do tamanho de partícula do alimento diminui a digestibilidade da fibra bruta. Também foi observada diferença $(\mathrm{P}<0,05)$ no consumo da MS do alimento, que foi maior nos animais que receberam o alimento com menor tamanho de partícula.

Segundo Drogoul et al. (2000), as variações na digestibilidade dos nutrientes quando se compara o fornecimento de feno em diferentes formas físicas para 
Tabela 3 - Coeficientes de digestibilidade dos nutrientes em equinos alimentados com feno de coast-cross em diferentes formas físicas

\begin{tabular}{lccccc}
\hline Coeficiente de digestibilidade (\%) & \multicolumn{3}{c}{ Feno de coast-cross } & \multicolumn{2}{c}{ Média CV (\%) } \\
\cline { 2 - 5 } & Inteiro & Picado (5 cm) & Moído (5 mm) & Moído (3 mm) \\
\hline Matéria seca & 60,5 & 59,2 & 61,5 & 59,9 & 60,3 \\
Proténa bruta & 64,4 & 64,7 & 63,9 & 63,5 & 64,1 \\
Fibra em detergente ácido & 63,4 & 59,9 & 65,4 & 61,2 & 61,5 \\
Fibra em detergente neutro & 62,9 & 61,9 & 64,4 & 63,1 & 63,1 \\
Celulose & 66,3 & 63,9 & 68,2 & 65,4 & 65,9 \\
Hemicelulose & 62,6 & 63,3 & 63,6 & 64,5 & 63,5 \\
Energia bruta & 58,8 & 57,3 & 58,7 & 58,1 & 3,80 \\
\end{tabular}

Médias nas linhas não diferem entre si $(\mathrm{P}>0,05)$ pelo teste SNK

equinos ocorrem em razão do maior consumo de matéria seca quando o feno moído e peletizado é fornecido em substituição ao feno inteiro.

Tood et al. (1995) comentaram que as variações nas respostas da digestibilidade dos nutrientes observadas nas pesquisas com diferentes tamanhos de partícula do alimento podem ter como causa os métodos utilizados para determinação da digestibilidade dos nutrientes. Esses autores utilizaram o método indireto, com indicador, para determinação da digestibilidade dos nutrientes em comparação ao método de coleta total. Os resultados demonstraram que o uso do indicador não foi satisfatório, pois subestimou os valores de digestibilidade dos nutrientes em relação aos valores determinados por coleta total de fezes, o que pode ser explicado pela baixa recuperação deste indicador nas fezes. Segundo Maurício et al. (1996), o método de coleta total de fezes é o mais recomendado para experimentos de digestibilidade em equinos, em virtude da maior precisão nos resultados dos coeficientes de digestibilidade.

Os valores médios dos coeficientes de digestibilidade da MS, PB, FDA, FDN, celulose, hemicelulose e energia bruta do feno de coast-cross deste trabalho, com exceção dos valores de hemicelulose, foram superiores aos observados por Almeida et al. (1999), que observaram valores dos coeficientes de digestibilidade da MS, PB, FDA, FDN, celulose, hemicelulose e energia bruta de 46,8 ; 56,$1 ; 44,6 ; 63,3 ; 54,3 ; 83,5$ e 47,9\%, respectivamente.

Araújo et al. (2000) e Perali et al. (2001), avaliando o feno de coast-cross em equinos, observaram valores dos coeficientes de digestibilidade da MS, PB, EB, FDN, FDA e hemicelulose de 43,$5 ; 40,4 ; 42,9 ; 45,7 ; 34,7$ e $55,6 \%$, e de 43,$0 ; 40,1 ; 42,3 ; 45,2 ; 34,3 ;$ e $34,5 \%$, respectivamente. Os valores obtidos nesta pesquisa foram superiores, entretanto, parte dessa diferença pode ser explicada por desigualdade na composição nutricional desses fenos.

Oliveira et al. (2003), utilizando o feno de coast-cross como único alimento para equinos, observaram coeficientes de digestibilidade da MS, PB, FDN, FDA e energia bruta de
67,$3 ; 64,0 ; 71,2 ; 44,6$ e $33,6 \%$, respectivamente, valores equivalentes aos observados neste trabalho, exceto para a fração fibrosa do alimento, que apresentou menor digestibilidade. As diferenças nos coeficientes de digestibilidade podem estar associadas à qualidade do feno de coast-cross, pois os fenos utilizados por esses autores apresentaram maior porcentagem da fração fibrosa e menor porcentagem de PB. Os teores médios da PB, FDN, FDA e lignina foram, respectivamente, de 6,27;88,55; 45,97 e 6,95\% (Almeida etal., 1999) e de 6,41;84,64; 40,15 e 9,10\% (Araújo et al., 2000). Os fenos de coast-cross utilizados por Perali et al. (2001) e por Oliveira et al. (2003) apresentaram os seguintes teores de PB, FDN e FDA, de 4,71; 70,32 e $42,88 \%$ e de 7,$3 ; 75,7$ e $40,6 \%$, respectivamente.

Não foi observada diferença $(\mathrm{P}>0,05)$ nos valores médios do consumo de matéria seca, proteína, energia e FDN digestíveis dos diferentes tamanhos de partícula do feno de coast-cross (Tabela 4). O consumo médio diário total de energia digestível foi superior à exigência diária em energia digestível recomendada pelo NRC (1989) para cavalos com $200 \mathrm{~kg}$ de peso vivo em mantença, que é de 7,4 Mcal de ED por dia.

Não foi observada diferença $(\mathrm{P}>0,05)$ no consumo diário de água, expresso em litros ou litros $/ \mathrm{kg}$ de MS ingerida, com média de 23,6 litros e 4,71 litros/kg de MS ingerida (Tabela 5), desta forma, o fornecimento do feno moído não teve influência sobre o consumo de água dos animais. Segundo Lewis (2000), o consumo de água dependerá da quantidade de água no alimento ingerido, da temperatura, da umidade ambiental, do exercício e do estado fisiológico do animal.

Cymbaluk (1989) observou consumo de água de 3,2 litros/kg de matéria seca ingerida quando o feno de gramínea foi fornecido como dieta única para os equinos. Pearson \& Merritt (1991) também observaram consumo hídrico inferior ao deste estudo, com valores médios entre 1,92 e 2,97 litros/kg de matéria seca na dieta com feno ou com palha respectivamente. 
Tabela 4 - Consumo médio diário de matéria seca, proteína, energia e fibra em detergente neutro digestíveis em equinos alimentados com feno de coast-cross sob diferentes formas

\begin{tabular}{lccccc}
\hline & \multicolumn{2}{c}{ Feno de coast-cross } & \multicolumn{2}{c}{ Média } & \multicolumn{2}{c}{ CV (\%) } \\
\cline { 2 - 5 } & Inteiro & Picado $(5 \mathrm{~cm})$ & Moído $(5 \mathrm{~mm})$ & Moído $(3 \mathrm{~mm})$ & 2,92 \\
\hline MS digestível (kg/dia) & 2,91 & 2,87 & 2,91 & 2,99 & 2,63 \\
Proteína digestível (kg/dia) & 0,38 & 0,39 & 0,37 & 0,39 & 3,05 \\
Energia digestível (Mcal/dia) & 12,13 & 11,92 & 11,89 & 12,42 & 12,09 \\
FDN digestível (kg/dia) & 2,14 & 2,12 & 2,15 & 2,22 & 2,16 \\
\hline
\end{tabular}

Médias nas linhas não diferem entre si $(\mathrm{P}>0,05)$ pelo teste SNK.

Cuddeford et al. (1995), avaliando o consumo de água em equídeos alimentados com diferentes proporções de alfafa e palha de aveia na dieta, não observaram diferença no consumo de água medido em litros por $\mathrm{kg}$ MS. O consumo médio diário variou de 2,76 a 3,27 litros por kg de MS consumido, respectivamente, para a dieta contendo somente alfafa ou somente palha de aveia.

O consumo de água observado neste trabalho foi de 4,71 litros de água/kg MS. Oliveira et al. (2003) avaliaram o consumo hídrico de equinos em condições experimentais semelhantes às deste estudo e observaram consumo de 13,78 litros de água e de 3,97 litros de água $/ \mathrm{kg}$ de matéria seca em equinos recebendo feno de capim coast-cross como único alimento. Bretas et al. (2007), também em condições experimentais similares e utilizando feno de tifton- 85 como único alimento da dieta de equinos, observaram consumo de água de 13,13 litros e 5,37 litros $/ \mathrm{kg}$ MS ingerida.

A excreção de água, tanto pelas fezes quanto pela urina, assim como a excreção total, não diferiu $(\mathrm{P}>0,05)$ nos animais consumindo feno de coast-cross nas diferentes formas físicas, com valores médios de 7,97; 5,18 e 13,16 litros, respectivamente, o que demonstra que a forma de fornecimento do feno não afetou a excreção de água pelos animais.

Cymbaluk (1989) sugeriu que mais água pode ser retida na digesta do cólon quando equinos são alimen- tados com feno, e a excreção de água fecal também aumentou com o fornecimento de feno de gramínea. O aumento do conteúdo da fibra na dieta tem efeito direto sobre o teor de umidade das fezes, pois, em virtude da menor digestibilidade da fração fibrosa, há maior excreção fecal desta fração, o que aumenta tanto a massa fecal quanto o seu teor hídrico. Desta forma, espera-se aumento do consumo de água quando se tem dieta rica em fibra (Lewis, 2000).

Houve diferença $(\mathrm{P}<0,05)$ no balanço hídrico dos equinos alimentados com feno nas diferentes formas, que foi maior nos animais alimentados com feno picado $(5 \mathrm{~cm})$ ou feno finamente moído $(3 \mathrm{~mm})$ em relação aos alimentados com feno inteiro e feno moído ( $5 \mathrm{~mm})$, com valores de 11,98 e 12,34 vs 8,85 e $8,86 \mathrm{~L} /$ dia, respectivamente. $\mathrm{O}$ aumento no balanço hídrico não foi influenciado somente pelo tamanho de partícula do feno, pois não houve diferença $(\mathrm{P}>0,05 \%)$ no balanço hídrico dos animais consumindo o feno inteiro e moído a $5 \mathrm{~mm}$. Considerando que o feno utilizado nas dietas foi o mesmo, que o consumo de matéria seca e de água expresso em $\mathrm{kg}$ MS/dia foram similares e que a digestibilidade dos nutrientes não diferiu entre as formas de processamento do feno de coast-cross, a maior retenção de água pode estar relacionada ao tempo de consumo da dieta e à taxa de passagem da fase líquida da digesta no trato gastrintestinal.

Tabela 5 - Consumo de água, excreção fecal de água, excreção urinária de água, excreção total de água e balanço hídrico em equinos alimentados com feno de coast-cross de diferentes formas físicas

\begin{tabular}{|c|c|c|c|c|c|}
\hline Água & \multicolumn{4}{|c|}{ Feno de coast-cross } & $\mathrm{CV}(\%)$ \\
\hline Consumo água (L/dia) & $21,52 \pm 2,67$ & $24,72 \pm 0,87$ & $21,85 \pm 1,92$ & $26,31 \pm 1,12$ & 9,0 \\
\hline Excreção fecal (L/dia) & $8,09 \pm 1,42$ & $7,89 \pm 1,31$ & $7,64 \pm 0,66$ & $8,24 \pm 0,56$ & 9,8 \\
\hline Excreção urinária (L/dia) & $4,82 \pm 0,57$ & $4,83 \pm 1,06$ & $5,36 \pm 0,84$ & $5,73 \pm 0,48$ & 18,3 \\
\hline Excreção total (L/dia) & $12,92 \pm 1,52$ & $12,74 \pm 1,97$ & $13,00 \pm 0,97$ & $13,97 \pm 1,03$ & 10,5 \\
\hline
\end{tabular}

Médias, nas linhas, seguidas de letras diferentes diferem $(\mathrm{P}<0,05)$ entre si pelo teste $\mathrm{SNK}$. 


\section{Conclusões}

O consumo total de nutrientes não é alterado pela redução do tamanho de partícula, mas equinos consomem mais rapidamente o feno de coast-cross quando fornecido com tamanho de partícula reduzido, entretanto, o processamento do feno de coast-cross não influencia a digestibilidade dos nutrientes. As formas físicas do feno de coast-cross estudadas têm efeito no balanço hídrico, mas não há relação direta entre a redução do tamanho da partícula do feno e o aumento da retenção de água.

\section{Agradecimentos}

À Fundação de Amparo a Pesquisa do Estado do Rio Janeiro, pelo apoio financeiro.

\section{Literatura Citada}

ALMEIDA, M.I.V.; FERREIRA, W.M.; ALMEIDA, F.Q. et al. Valor nutritivo do capim-elefante (Penninsetum purpureum, Shum), do feno de alfafa (Medicago sativa, L.) e do feno de capim coast-cross(Cynodon dactylon (L.) Pers.) para eqüinos. Revista Brasileira de Zootecnia, v.28, n.4, p.743-752, 1999.

ARAÚJO, K.V.; LIMA, J.A.F.; FIALHO, E.T. et al. Comparação da técnica do saco de náilon móvel com o método de coleta total na determinação da digestibilidade dos nutrientes de alimentos volumosos em eqüinos. Revista Brasileira de Zootecnia, v. 29, n. 3, p. $752-761,2000$.

ASSOCIATION OF OFFICIAL ANALYTICAL CHEMISTS - AOAC. Official methods of analysis. 12.ed. Washington, D.C.: 1975. $1094 \mathrm{p}$.

BRETAS, A.A.; ALMEIDA, F.Q.; VIEIRA, A.A. et al. Balanço hídrico e de nitrogênio em eqüinos alimentados com feno de alfafa e feno de tifton-85 e concentrado. Revista Brasileira de Ciência Veterinária, v.14, n.3, p.150-154, 2007.

CUDDEFORD, D.; PEARSON, R.A.; ARCHIBALD, R.F. et al. Digestibility and gastro-intestinal transit time of diets containing different proportions of alfalfa and oat straw given to Thoroughbreds, Shetland ponies, Highland ponies and donkeys. Animal Science, v.61, p.407-417, 1995.

CYMBALUK, N.F. Water balance of horses fed various diets. Equine Practice, v.11, n.1, p.19-24, 1989.

DROGOUL, C.; PONCET, C; TISSERAND, J.L. Feeding ground and pelleted hay rather than chopped hay to ponies. 1. Consequences for in vivo disgestibility and of passage de digesta. Animal Feed Science and Technology, v.87, p. $117-130,2000$.

FOMBELLE, A.; JACOTOT, E; DROGOUL, C. et al. Effects of the hay:grain on digestive physiology and microbial ecosystem in ponies. In: EQUINE NUTRITION AND PHYSIOLOGY SOCIETY SYMPOSIUM, 16., 1999, Raleigh. Proceedings... Raleigh: ENPS, 1999, p.151.
FRAPE, D.L. Equine nutrition and feeding. 2.ed. Oxford: Blackwell Science, 1998. 549p.

HAENLEIN, G.F.W.; HOLDREN, R.D.; YOON, Y.M. Comparative response of horses and sheep to different physical forms of alfafa hay. Journal of Animal Science, v.25, p.740-743, 1966.

HINTZ, H.F.; CYMBALUK, N.F. Nutrition of the horse. Annual Review of Nutrition, v.14, p.243-267, 1994.

HINTZ, H.F.; LOY, R.G. Effect of pelleting on the nutritive value of horses rations. Journal of Animal Science, v.25, p.10591060, 1966.

LEWIS, L.D. Nutrição clínica eqüina. 1.ed. São Paulo: Roca, 2000. $710 \mathrm{p}$.

MAURÍCIO, R.M.; GONÇALVES, L.C.; RESENDE, A.C. et al. Determinação da digestibilidade aparente em eqüinos através do óxido crômico, da lignina e da coleta total de fezes. Arquivo Brasileiro de Medicina Veterinária e Zootecnia, v.48, n.6, p.703-711, 1996.

MEYER, H. Alimentação de cavalos. São Paulo: Varela, 1995 $303 \mathrm{p}$.

NATIONAL RESEARCH COUNCIL - NRC. Nutrient requirements of horses. 5.ed. Washington, D.C.: National Academy Press, 1989. $100 \mathrm{p}$.

OLIVEIRA, C.A.A. Digestibilidade de nutrientes e cinética de passagem da digesta em dietas com diferentes níveis de volumoso para eqüinos. 2001. 80f. Dissertação (Mestrado em Zootecnia) - Universidade Federal Rural do Rio de Janeiro, Seropédica, 2001.

OLIVEIRA, C.A.A.; ALMEIDA, F.Q.; VIEIRA, A.A. et al. Cinética de passagem da digesta, balanço hídrico e de nitrogênio em eqüinos consumindo dietas com diferentes proporções de volumoso e concentrado. Revista Brasileira de Zootecnia, v.32, n.1, p.140-149, 2003.

PEARSON, R.A.; MERRIT, J.B. Intake, digestion and gastrointestinal transit in resting donkeys and ponies and exercised donkeys given ad libitum hay and straw diets. Equine Veterinary Journal, v.23, n.5, p.339-343, 1991.

PERALI, C.; LIMA, J.A.F.; BERTECCHINI, A.G. et al. Valores nutricionais de alimentos pra eqüinos. Ciência e Agrotecnologia, v.25, n.5, p.1216-1224, 2001.

SCHNEIDER, B.H.; FLATT, W.P. The evaluation of feeds through digestibility experiments. Athens: The University of Georgia Press, 1975. 423p,

TASKER, J.B. Fluid and electrolyte studies in the horse. II. An apparatus for the collection of total daily urine and faeces from horses. Cornell Veterinarian, v.56, n.1, p.77-84, 1966

TOOD, L.K.; SAUER, W.C.; CHIRSTOPHERSON, R.J. et al. The effect of feeding different forms of alfalfa on nutrient digestibility and voluntary intake in horses. Journal of Animal Physiology and Animal Nutrition, v.73, p.1-8, 1995.

UDÉN, P. The effect of grinding and pelleting hay on digestibility, fermentation rate, digesta passage and rumen and particle size in cows. Animal Feed Science and Technology, v.19, p.145-157, 1988 .

UNIVERSIDADE FEDERAL DE VIÇOSA - UFV. SAEG - Sistema de análises estatísticas e genéticas (Manual do usuário). Viçosa, MG: 2004. 150p.

Van SOEST, P.J.; ROBERTSON, J.P.; LEWIS, B.A. Methods for dietary fiber, neutral detergent fiber, and nonstarch polysaccharides in relation to animal nutrition. Journal of Dairy Science, v.74, p.3583-3597, 1991. 